\title{
Intrauterine insemination of sows by using a two- chamber semen bag system
}

\author{
A.K. Olesen' and C. Hansen' \\ 'Danish Pig Production, Axeltorv 3, 1609 Copenhagen V. Denmark
}

Artificial insemination of sows is an effective method for intensive use of high breeding value boars. In sows, intracervical insemination $(\mathrm{ICl})$ using 2 to 3 billion spermatozoa is an established method worldwide, resulting in a consistently high fertility (Watson et al. 2002). Using intrauterine insemination, the number of spermatozoa per insemination can be reduced even further. In intrauterine insemination (IUI), the tip of the catheter is placed in the corpus uteri depositing the semen even closer to the site of fertilization in the oviduct (Vazquez et al. 2008). If IUI can be performed as easily and efficiently as $\mathrm{ICl}$, this will result in more semen doses per boar. This will allow a stronger selection among boars, and lower the costs per dose. This study investigated the effect on fertility, when reducing the amount of sperm per dose using IUI.

A total of 9272 multiparous Danish Landrace $\times$ Large White crossbred sows from seven Danish commercial herds were randomly distributed into three groups as shown in table 1. All sows were inseminated using heterospermic semen from Danish Duroc boars. Semen was collected using the gloved hand method collecting the whole ejaculate. Semen quality was evaluated using subjective microscopic motility score. Semen concentration was measured using NucleoCounter SP100. Semen was extended using EDTA boar semen extender. The same batch of semen comprising semen from 6 to 10 boars was used in all three groups in each herd. One dose from each batch was analysed for content of sperm per dose using SP100.

Table 1. Method of insemination, no. sperm per dose and volume in the three groups.

\begin{tabular}{llcc}
\hline Group & Method of AI & No. Sperm per dose & Volume (L) \\
\hline ICI & Traditional AI with normal bag & $2 \times 109$ & 80 \\
IUI-750 & IUI with Iwo-chambered bag & $750 \times 106$ & $30^{*}+50$ \\
IUI-500 & IUI with two-chambered bag & $500 \times 106$ & $20^{*}+60$ \\
\hline
\end{tabular}

* volume of chamber containing extended semen

Estrus detection was performed for all sows daily from day 4 after weaning using the "fivepoint-plan" as described by Madsen et al. (2002). Prior to insemination, sows were stimulated according to the "five-point-plan". A boar was present in front of the sows during insemination. Sows were inseminated when estrus was detected and inseminated at 24-hour intervals, until standing reflex was no longer present. All inseminations (ICI and IUI) were carried out by farm workers. Before the IUI, the farm workers had been thoroughly instructed by a veterinarian. For intracervical insemination, a standard semen bag was used. To avoid a negative dilution effect when using the low number of sperm for the IUI, a Porcivet two-chamber bag Uoergen Kruuse A/S, Denmark) was used. One chamber was filled with extended semen, the other chamber contained EDTA-extender. Prior to insemination, the semen and extender were mixed in the double-chambered bag. A traditional flexible foam tip catheter was used for intracervical insemination. The catheter used for intrauterine insemination was the Porcivet Cervi-slip catheter (Jergen Kruuse AS, Denmark). The tip of the IUI catheter was fixed in the cervical canal after which the inner catheter was led gently through the cervix into the uterus.

E-mail: aki@dansksvineproduktion.dk. 
Analyses of semen doses showed a mean content of $2093 \times 10^{6}, 764 \times 10^{6}$ and $510 \times 10^{6}$ sperm per dose for ICI, IUI750 and IUI500, respectively. The deviation was 249,70 and 43 respectively. This is as expected during production of semen doses and is therefore estimated not to have an influence on the results of this trial.

The average parity in all three groups was 4.1. Farrowing rate and total number of piglets born are shown in table 2 .

Table 2. Number of sows and results achieved in the three groups.

\begin{tabular}{lcccc}
\hline Group & Total number of sows & Total number of litters & Farrowing rate & $\begin{array}{c}\text { Total born piglets per } \\
\text { litter }\end{array}$ \\
\hline ICI & 3,099 & 2,793 & 90.2 & $16.5^{*}$ \\
IUI-750 & 3,077 & 2,807 & 91.3 & 16.3 \\
IUI-500 & 3,021 & 2,684 & 88.9 & $16.2^{*}$ \\
\hline
\end{tabular}

* Significant different $(p<0.05)$

A significant difference of 0.3 total piglet per litter $(P=0.0139)$ was seen between the control group and IU1500. There was no significant difference in litter size between the control group and IUI750. There was no significant difference between the control group and the two IUIgroups in farrowing rate.

Intrauterine insemination could not be performed in 1.2 percent of the sows as the inner catheter could not pass through the cervix into the uterus. Whenever IUI was not possible, the sows were inseminated using $\mathrm{ICl}$. Sows inseminated using IUI did not show signs of pain or discomfort. At the beginning of the trial, attending farmers were mainly positive to IUI. However, thorough training in performing the technique is necessary. Also, they felt that IUI required more time than $\mathrm{ICI}$, since an extra catheter needed to be inserted.

Intrauterine insemination can lead to a significant reduction in the number of sperm per insemination under farm conditions - without affecting fertility negatively. The insemination dose containing heterospermic semen can be lowered from $2 \times 10^{9}$ to $750 \times 10^{6}$ sperm per dose with this technique. These results demonstrate that the total number of sperm needed for successful $\mathrm{Al}$ is far lower than the standard number of sperm per dose.

\section{References}

Madsen MT, Larsen M, Mathiasen J, Kindahl H, Einarsson S \& Madej A 2002. Plasma levels of oxytocin and $\mathrm{PGF}_{20}$ metabolite during $\mathrm{Al}$ and mating in multiparous sows. Reproduction in Domestic Animals 37242.

Vazquez JM, Roca J, Gil MA, Cuello C, Parrilla I, Caballero I, Vazquez IL \& Martínez EA 2008. Low- dose insemination in pigs: problems and possibilities. Reproduction in Domestic Animals 43523

Watson PF \& Behan JR 2002. Intrauterine insemination of sows with reduced sperm numbers: results of a commercially based field trial. Theriogenology 57 1683-1693. 